\title{
Modeling Impact of Natural Hazard-Induced Disasters on Income Distribution in the United States
}

\author{
Lin Fang ${ }^{1} \cdot$ Jiayu Wu ${ }^{1} \cdot$ Tatjana Miljkovic $^{1}$
}

Published online: 14 November 2017

(c) The Author(s) 2017. This article is an open access publication

\begin{abstract}
Economic damage due to hurricane activities has been shown to impact income inequality in the coastal states of the United States. We consider 17 other natural hazards, in addition to hurricanes, that affected the entire United States for the period 1970-2013. Two fixed effects models were developed to quantify the relationship between income inequality and economic and demographic variables, including crop and property losses from natural hazard-induced disasters. These models include state-byyear and region-by-year fixed effects models. Our findings show that the damages from all natural hazards impact income distribution across the United States, not only in hurricane-affected areas, but also in non-hurricane states. The results of our study have important implications for the insurance industry and government policymakers.
\end{abstract}

Keywords Disaster insurance - Gini

coefficient $\cdot$ Income distribution $\cdot$ Natural hazard-

induced disasters · United States

\section{Introduction}

Recent studies have demonstrated an increasing interest in how large-scale natural catastrophic events such as hurricanes, floods, and earthquakes can shock economies (Kim 2011). The geography literature shows that few countries

Senior authorship is shared between Lin Fang and Jiayu Wu.

Tatjana Miljkovic

miljkot@miamioh.edu

1 Department of Statistics, Miami University, Oxford, OH 45056, USA worldwide have escaped natural catastrophic events (Sproles 2015). For decades, most regions worldwide have experienced such events with high frequency and severity (Wisner et al. 2004). Local economies, thus, have been at great risk of collapsing due to these catastrophic events, and in severe cases, national economies are negatively impacted as well (Klomp 2016).

Different types and levels of catastrophic events can happen in different geographical areas across the United States (Fomby et al. 2013). In 2005, after Hurricane Katrina hit New Orleans, $7.6 \%$ of people in the labor force were unemployed in areas with devastating conditions, compared to $6.0 \%$ in undamaged areas. Additionally, the people in poor areas are also more likely to live in buildings where there have already been high levels of damages (Logan 2008). These situations resulted in a large portion of the population in New Orleans surviving below the poverty line (Masozera et al. 2007). Richer areas are able to provide safer buildings, as well as adequate lifesaving shelters when facing nature's shocks, reducing the death toll and damages. The recognition that these damages caused by natural events have the capability to widen the income gap between affected areas has a twofold effect: (1) it raises the significance of the economic damages and recovery costs; and (2) it forces public service providers to rethink urban planning (Shaughnessy et al. 2010).

There is a growing literature focus on how the overall economy-both at the macro- and microlevel-will be affected by natural hazard-induced disasters. Catastrophic events have negative impacts on short- and long-term growth (Cavallo and Noy 2010). Yun and Waldorf (2016) analyzed the migratory responses and income losses after Hurricanes Katrina and Rita and pointed out that damage severity and individual resilience affect moving decisions. Their analysis of affected households suggested that low- 
income households that face relocation are more severely impacted than better-off people.

Leichenko and Silva (2014) studied the relationship between climate change and poverty and pointed out that climate change is not directly responsible for poverty. However, there are numerous ways in which climate change may exacerbate poverty, especially in less developed regions. Logan (2008) stated that poorer people are more likely to suffer higher levels of storm damages because a higher proportion of poor people live in areas that sustain higher levels of damages. Increasing attention is being paid to promoting factors that build resilience in poor populations.

Many experts in the field have also done research related to how hurricanes influence economic growth in more general terms. Miljkovic and Miljkovic (2014) showed that the damages from hurricane events have tended to further exacerbate income inequalities in the coastal states of the United States throughout the last century. If hurricanes continue to increase income inequalities in affected areas, relatively poorer people will continue to become poorer as time goes by, and the consequences will become critical for both the insurance industry and policymakers. The government will come under more pressure to offer assistance to poor families, both in the short and the long run.

Recently, U.S. agencies have shown interest in understanding community resilience to natural hazard-induced disasters as a more proactive community engagement with disaster risk reduction (Cutter et al. 2008). Norris et al. (2008) defined community resilience as a set of four adaptive capacities that include: economic development, social capital, information and communication, and community competence. According to Adger (2000) the key parameters of "social resilience" include economic growth, stability of livelihoods, and equitable distribution of income and assets within the population. We believe that one of the ways to measure community resilience through equitable distribution of income is to study the Gini coefficient for the population within impacted communities or regions. The Gini coefficient is a general measure of the income inequality among the population within a region. Nakata and Sawada (2007) established that income has a strong positive correlation with wealth. The wealth distribution in different regions may have an impact on the aggregate insurance demand. Nakata and Sawada (2007) found that the aggregate insurance demand should be smaller when the wealth inequality is larger, as measured by a higher Gini coefficient.

This study is motivated by the recent study by Miljkovic and Miljkovic (2014) on modeling the impact of hurricane damages on income distribution in the coastal United States. These authors found that an increase in normalized economic damages of USD 100 billion would lead to an increase in income inequality by $5.4 \%$ in the hurricane states of the United States, based on the data for the period 1910-2005 and measured by the Gini coefficient. Our research investigates whether income distribution is affected by natural hazard-induced disasters not only in the hurricane states, but also in the non-hurricane states of the United States. In addition to hurricane losses, we incorporate crop and property losses from 17 other natural hazards reported for the period 1970-2013 across the United States. We aim to predict the degree of income inequality based on the intensity of losses and other economic, sociodemographic, and political variables. In order to address this problem in various aspects, a more generalized state-level database is created including variables such as the annual Gini coefficient, gross domestic product (GDP), crop and property losses, percentage of people over 65 , proportion of nonwhite population, and type of state senate. We believe that it is important to investigate the impact of all other natural hazard-induced disasters along with other economic, political, and sociodemographic variables for the country as a whole.

\section{Methodology}

Two separate yearly fixed effects models were developed for the period 1970-2013, using states and regions as crosssectional dummies. In these panel-data models it is postulated that the Gini coefficient, as a dependent variable, is a function of a set of independent variables: economic losses, GDP, proportion of people aged 65 and over, proportion of nonwhite population, political dominance of the U.S. Senate, time trend, and cross-sectional dummies. In the state-specific fixed effects model, dummy variable coefficients measure the change in the cross-section intercept with respect to an omitted state in order to avoid issues with perfect collinearity. Alabama was chosen by R software to be the omitted state, but any other state could equally serve that purpose, as the results would not be changed qualitatively.

The choice of omitted state or base level is based on alphabetical order. In the region-specific fixed effects model, dummy variable coefficients measure the change in the cross-section intercept with respect to an omitted region, that is the Northeast (Table 1).

Our state-specific fixed effects model is defined as follows:

$\boldsymbol{y}=\alpha \boldsymbol{l}_{N T}+X \boldsymbol{\beta}+\boldsymbol{Z}_{\mu} \mu+\boldsymbol{\varepsilon}$

where $y$ is the vector of the Gini coefficients dimension $N T \times 1, X$ is a design matrix size $N T \times K, Z_{\mu}$ is a matrix of state dummy variables $\left[\boldsymbol{Z}_{\mu}=\left[\boldsymbol{l}_{N T} X\right], \boldsymbol{l}_{N T}\right.$ is a vector of ones of dimension NT, $\boldsymbol{\beta}=\left(\beta_{1}, \ldots, \beta_{K}\right)$ ' is the vector of the 
Table 1 Definition of climate regions in the United States, based on the U.S. climate region map published by the National Oceanic and Atmospheric Administration (NOAA). Source https://www.ncdc.noaa.gov/monitoring-references/maps/us-climate-regions.php

\begin{tabular}{|c|c|}
\hline Region & States included \\
\hline Northeast & $\begin{array}{l}\text { Connecticut, Delaware, Maine, Maryland, Massachusetts, New Hampshire, New Jersey, New York, Pennsylvania, } \\
\text { Rhode Island, Vermont }\end{array}$ \\
\hline $\begin{array}{l}\text { Northern rockies and } \\
\text { plains }\end{array}$ & Montana, Nebraska, North Dakota, South Dakota, Wyoming \\
\hline Northwest & Idaho, Oregon, Washington \\
\hline Ohio valley & Illinois, Indiana, Kentucky, Missouri, Ohio, Tennessee, West Virginia \\
\hline South & Arkansas, Kansas, Louisiana, Mississippi, Oklahoma, Texas \\
\hline Southeast & Alabama, Florida, Georgia, North Carolina, South Carolina, Virginia \\
\hline Southwest & Arizona, Colorado, New Mexico, Utah \\
\hline Upper midwest & Iowa, Michigan, Minnesota, Wisconsin \\
\hline West & California, Nevada \\
\hline
\end{tabular}

regression coefficient to be estimated, and $\varepsilon$ is the vector of independent identically distributed (i.i.d.) random variables with mean zero and variance $\sigma^{2}$.

Our region-specific fixed effects model is similar to Eq. (1); however, the cross-sectional dummies are based on the regions defined in Table 1. Each region represents a group of states that share the same boundaries and have common climate characteristics. In order to employ this fixed effects model, it is assumed that there is no withinstate or within-region serial correlation. The $F$ test statistics are used to determine the usefulness of the model. The proportion of explained variability in the model is measured with the coefficient of determination, $R^{2}$. As noted by Miljkovic and Miljkovic (2014), it would be ideal to be able to convert the data into natural logarithms to make the coefficient estimates reported in the form of elasticity; however, the numerous zeroes presented in economic losses prevent this transformation.

\section{Data Description}

This study employed several annual state-specific data sets for the period from 1970 through 2013 for the contiguous United States. These data sets include the economic and sociodemographic variables described below with their corresponding sources.

\subsection{Gini Coefficient}

According to Morgan (1962), the Gini coefficient is the best single measure of inequality, which refers to the uneven income distribution among a population. It ranges from 0 (income is equally distributed among the members of society) to 1 (perfect inequality). Data for the Gini coefficient by state and year were compiled in "The U.S. Income Inequality Page of Mark W. Frank" (2015), based on the individual tax filing data available from the Internal Revenue Service. Figure 1 compares the Gini coefficient for three different time periods: 1970, 1990, and 2013. The darker spectrum of colors on the maps indicates a higher Gini coefficient, that is more income inequality. It is obvious that there has been a steady increase in income inequality since 1970 and that some states are impacted more than others. The left panel of Fig. 2 shows the trend for the Gini coefficient of hurricane and non-hurricane states for the period 1970-2013. There is a steep increase in Gini coefficient for both hurricane and non-hurricane states. While both types of states follow the same rate of increase in Gini coefficient between 1970 and 1990, there seems to be a slight departure in the rate of increase in Gini coefficient between hurricane and non-hurricane states for the period 1990-2013.

\subsection{Direct Economic Damages}

Changnon (1996) defined economic damages as the direct losses associated with the impacts of a natural hazard-induced disaster, as determined in the weeks after the losses occurred. Ibarraran et al. (2009) demonstrated that the cumulative effect has more notable macroeconomic impacts as economic damages become larger and can further increase existing income inequalities and lower income levels. The state-level data on catastrophic events with their direct property and crop damages were compiled from two different sources.

The data on crop and property damages in current dollars, from 17 different natural hazards, excluding property damages from hurricanes, were obtained from the Spatial Hazard Events and Losses Database for the United States 
1970
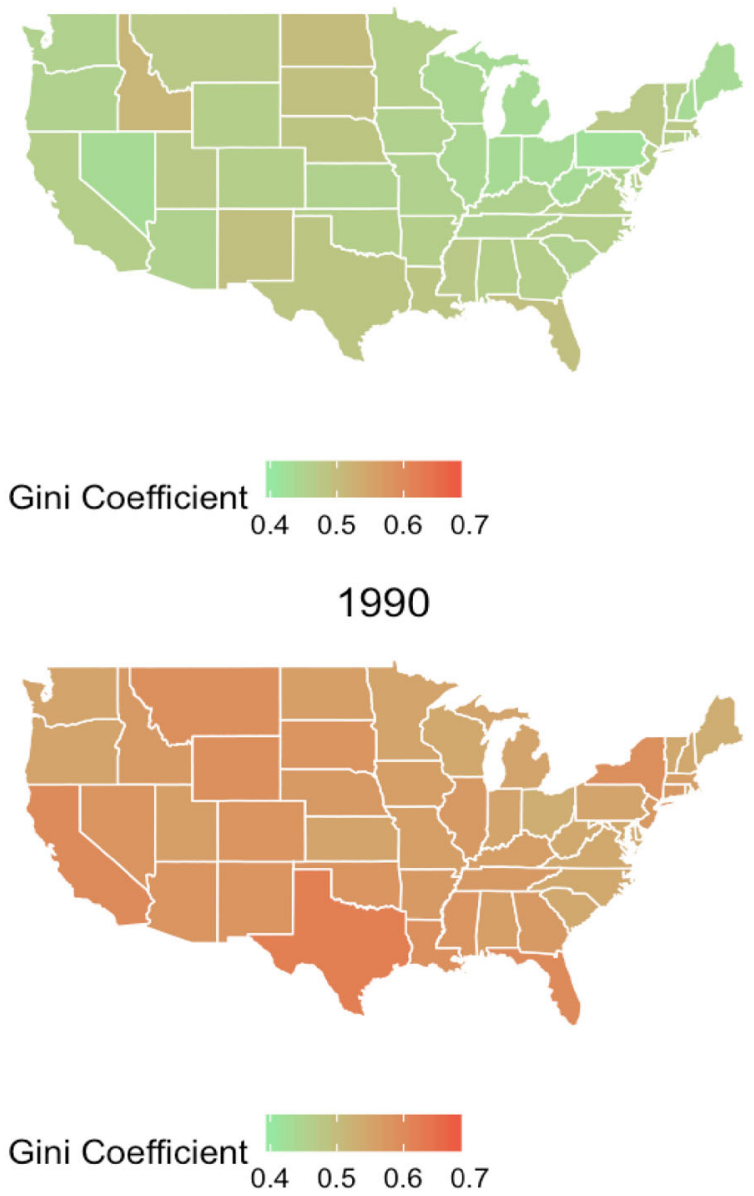

2013

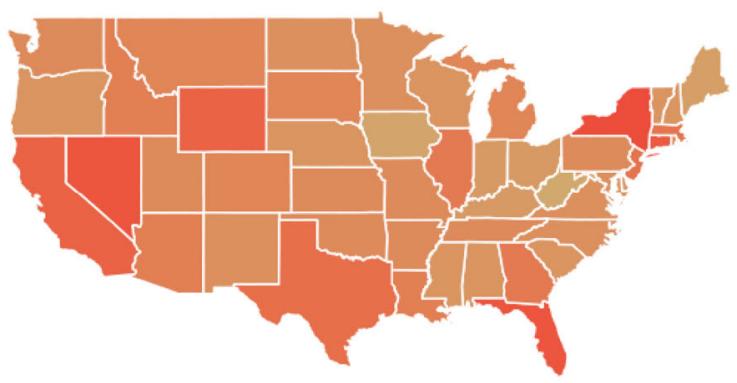

Gini Coefficient $\begin{array}{llll}0.4 & 0.5 & 0.6 & 0.7\end{array}$

Fig. 1 Gini coefficient maps of the United States by state for three selected years. Data source The U.S. Income Inequality Page of Mark W. Frank (2015), http://www.shsu.edu/eco_mwf/inequality.html

(SHELDUS $^{\mathrm{TM}}$ ) developed by the Hazards and Vulnerability Research Institute (2015) at University of South Carolina. To be consistent with the previous research (Miljkovic and Miljkovic 2014), the data on property losses
(PL) from past hurricanes were obtained from Pielke et al. (2008) for the period prior to 2006. These hurricane-caused property losses were further normalized at current value to account for wealth adjusted by inflation and percent change in population growth using the methodology proposed by Brunkard et al. (2008). This database was updated to include property losses from the most recent hurricanes (post-2008) by utilizing the information from the ICAT Damage Estimator (2017) Web site.

The inclusion of crop damages in this study is important because agricultural areas represent a large portion of the United States where the population density is low, and agricultural production represents an important share of the overall GDP in the United States. Thus, we believe that crop losses should be included in this analysis because they may deteriorate farming business needs and overall state income level.

\subsection{Gross Domestic Product}

Cavallo et al. (2013) showed that extremely large catastrophes were followed by an important decline in GDP per capita in both the short and the long run. Empirical studies have suggested a positive relationship between economic growth and income inequality in the United States since the 1970s (Majumdar and Partridge 2009). Thus, in order to measure economic growth by state over the same period we included historical data on state GDP (in million USD), as provided by the United States Bureau of Economic Analysis (2017) for 2015. Figure 3 shows how the aggregate GDP changed over time across different regions. The definition of regions is presented in Table 1 based on the U.S. climate region map published by the National Oceanic and Atmospheric Administration (NOAA). The Northeast region had the highest rate of increase in GDP, while the Northern Rockies and the Northwest had the smallest increase in GDP for the same period 1970-2013.

\subsection{Proportion of the Population Age 65+}

According to Miljkovic and Miljkovic (2014), people over age 65 are most vulnerable to natural hazard-induced disasters. Therefore, this group is believed to reflect important changes in the sociodemographic profile of the population in response to disasters. State-level data for people age 65 and over were obtained from the United States Census Bureau (2017).

\subsection{Proportion of the Nonwhite Population}

Anbarci et al. (2005) showed that the losses from natural hazards impact greatly women, the young and elderly, and people of ethnic or racial minorities. State-level data for the 


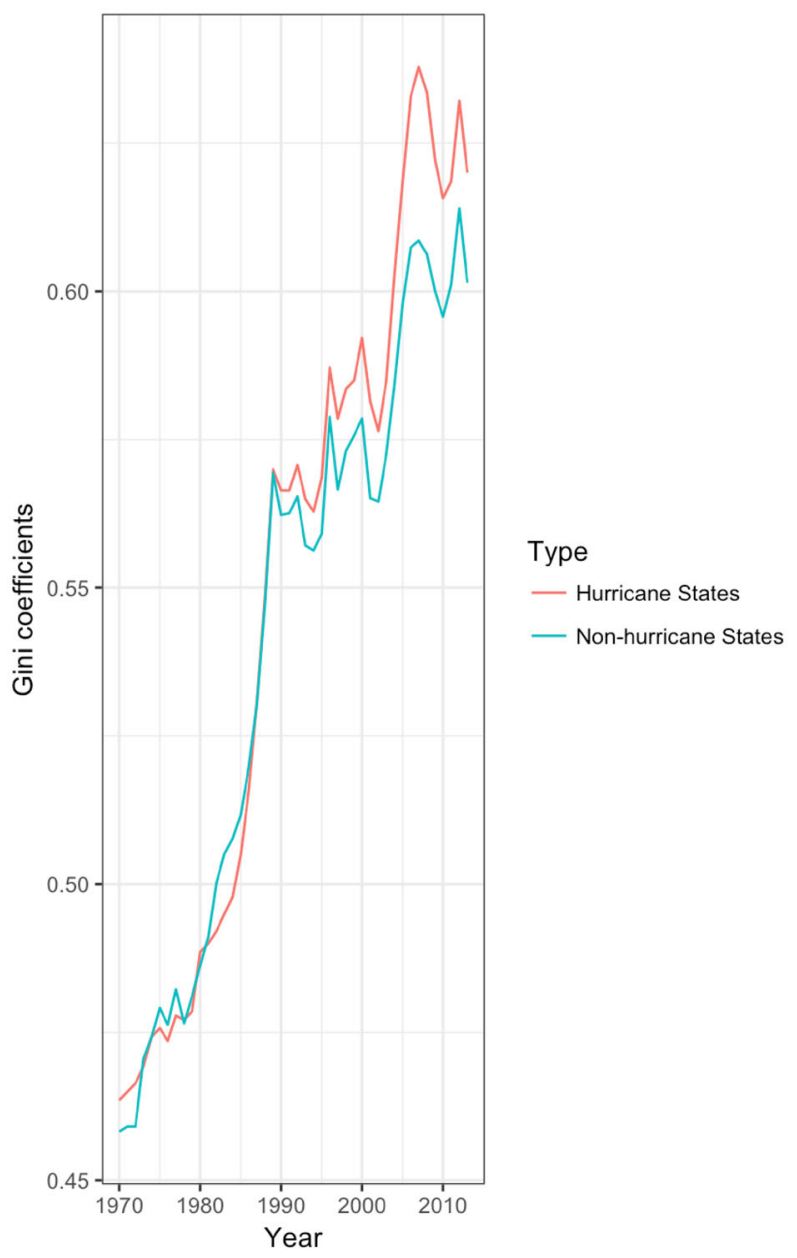

Fig. 2 Average Gini coefficients in the United States for the period 1970-2013, for hurricane versus non-hurricane states (left), and depending on a Democratic versus a Republican Senate (right). Data

proportion of the nonwhite population were obtained from the United States Census Bureau (2017).

\subsection{U.S. Senate}

Cavallo et al. (2013) concluded that natural hazard-induced disasters are unlikely to affect economic growth unless they trigger a radical political revolution. Therefore, the political affiliation of the party controlling the U.S. Senate was also considered in our model since the government stands in a position to provide financial aid to those in disaster-impacted areas. Data on the political affiliation (Democratic versus Republican-base level) of the President, Senate, and House of Representatives were obtained from U.S. Senate and U.S. Congress Web sites ${ }^{1}$ to test the hypothesis of Cavallo et al. (2013). The trend in Gini coefficient affected by the Senate variable is shown in the right panel of Fig. 2. The overall increasing trend in the

\footnotetext{
${ }^{1}$ http://www.senate.gov/; http://www.house.gov/.
}

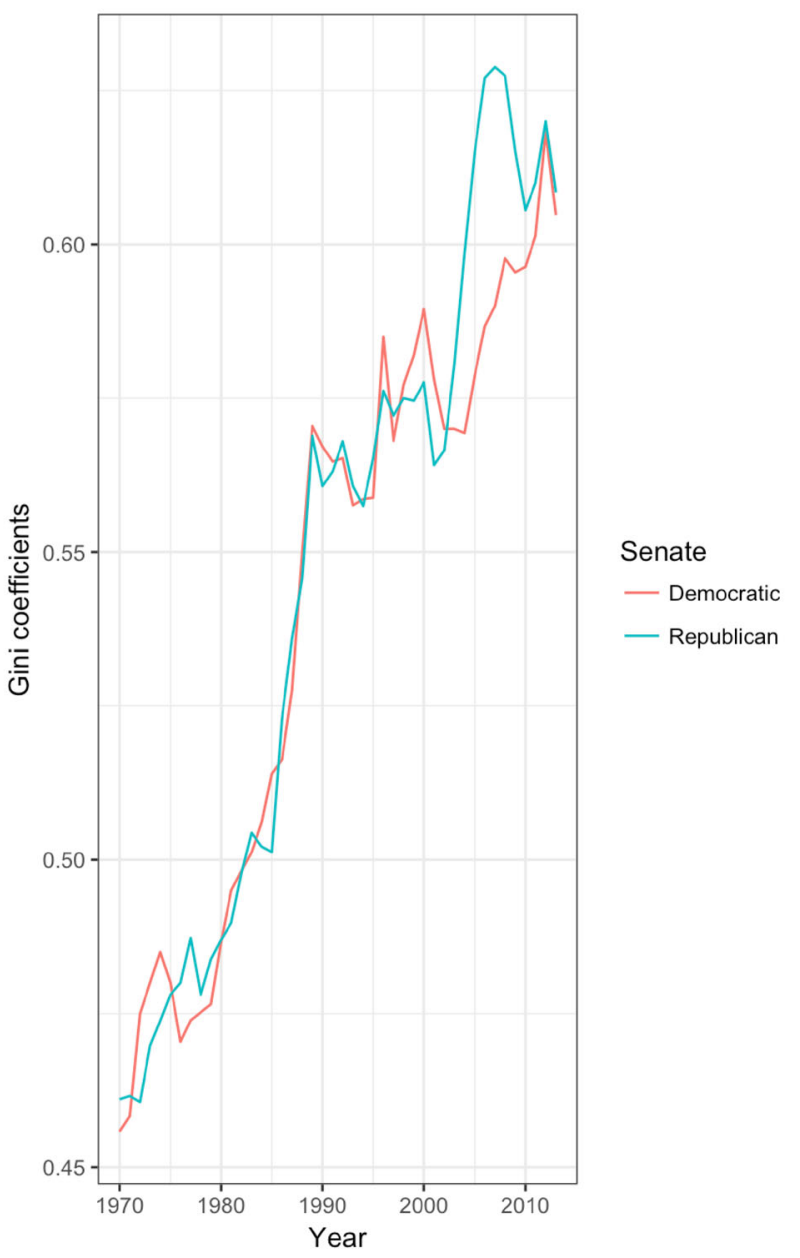

source The U.S. Income Inequality Page of Mark W. Frank (2015), http://www.shsu.edu/eco_mwf/inequality.html

Gini coefficient from both parties is observed. This trend diverges for the parties during the early 2000s.

\section{Analysis and Results}

We discuss our empirical results from the fixed-effects models and their implications. It is important to note that our results are based on a long time period (1970-2013). A short-term event such as the U.S. housing bubble during the mid-2000s, for example, would not have an impact on our results.

\subsection{Empirical Results}

The results of the state-specific and region-specific fixed effects models are presented in Tables 2 and 3. The analysis was conducted in R software (R Core Team 2016). The state/region-by-year fixed effects models were first run 

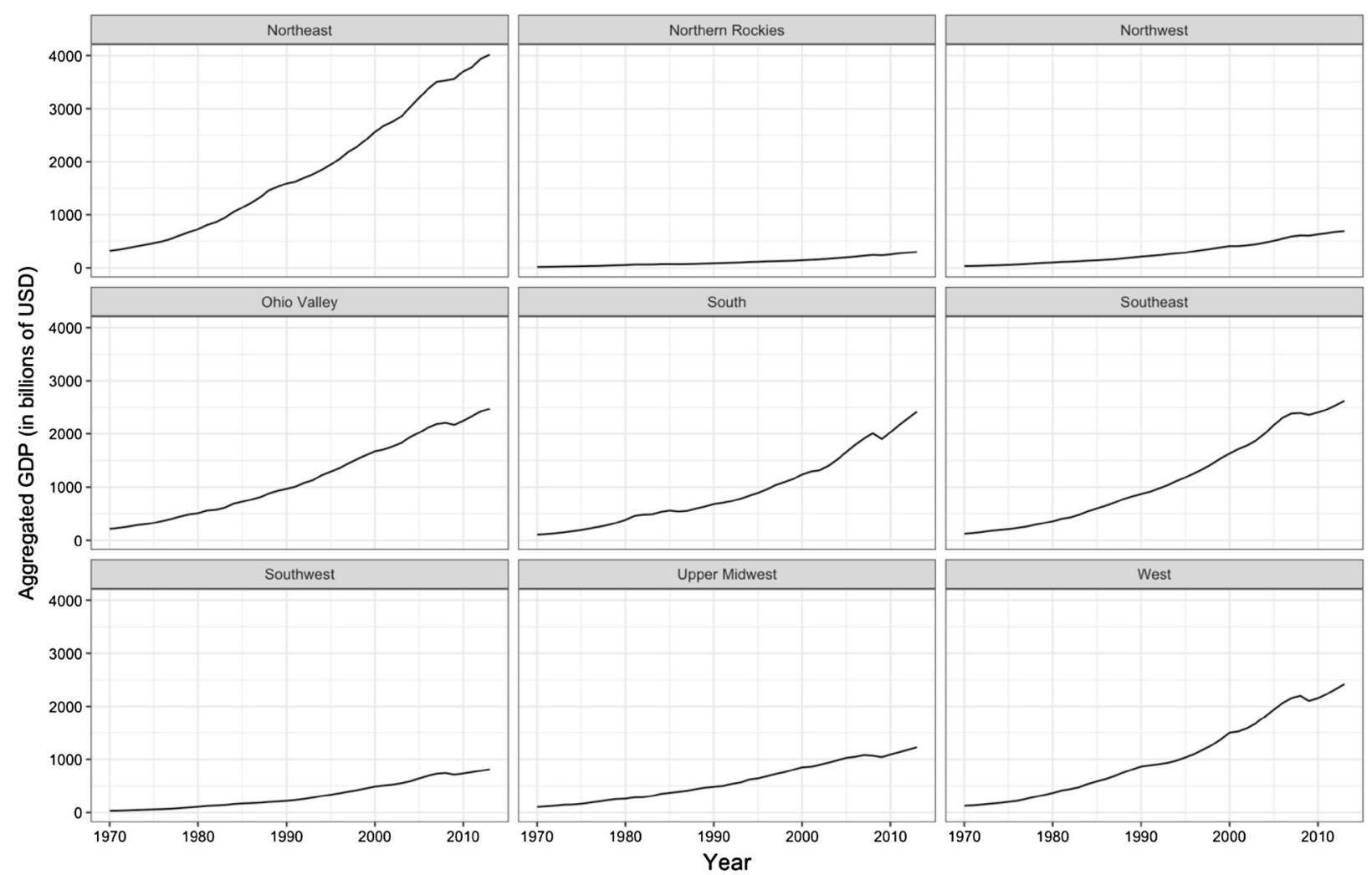

Fig. 3 Aggregated GDP (in billion USD) in the United States by climate region for the period 1970-2013

with all contemporaneous variables: GDP, economic damages, time trend, state dummies (with Alabama serving as the base/omitted state), and several socioeconomic variables - the political affiliation of the Senate (Republican as the base level), the proportion of the nonwhite population, and people aged over 65 .

The results in Table 2 indicate that the coefficients of state dummies for Arkansas, Colorado, Connecticut, Delaware, District of Columbia, Florida, Georgia, Idaho, Indiana, Iowa, Louisiana, Maine, Maryland, Michigan, Mississippi, Montana, Nebraska, Nevada, New Hampshire, New Mexico, New York, North Carolina, North Dakota, Ohio, Oklahoma, Pennsylvania, Rhode Island, South Carolina, South Dakota, Texas, Virginia, Washington, West Virginia, and Wyoming are all statistically significant. While the coefficients for GDP, time trend, and damages are all statistically significant, the coefficients for proportion of nonwhite people, proportion of people age $65+$, and type of Senate are not statistically significant. In this model, the dependent lagged variable for the Gini coefficient is statistically significant indicating that the Gini coefficient at time $t$ is highly related to the Gini coefficient at time $t-1$. A positive time trend coefficient suggests that there is an autonomous increase in income inequality over time, with the Gini coefficient increasing by 0.0037 per year, after allowing for the effects of all other predictors in the model. The coefficient for economic damages (both crop and property damages) is $2.77 \mathrm{E}-13$ for the period 1970 to 2013, indicating that an increase in economic damages by USD 100 billion leads to an increase in the Gini coefficient of about $2.77 \%$.

The coefficient for GDP indicates that an increase of annual GDP by USD 1000 billion leads to an increase in the Gini coefficient of about 0.032 or $3.2 \%$. The unit of GDP is million USD. It means that growth in nationwide income leads to a wider spread of income distribution and increases the gap of income inequality, in spite of the fact that the Gini coefficient is relatively inelastic (Miljkovic and Miljkovic 2014). This result is actually consistent with the suggestion Majumdar and Partridge (2009) made that the increase in economic inequality is coupled with the national economic growth across the United States and that the poor become poorer. The last three coefficients in the model are non-significant. The value of the adjusted $R$ squared in Table 2 is 0.873 , which indicates that the model fits well. The value of the $F$ statistic indicates that the model is useful for the prediction.

Overall, the results obtained from the state model further confirm the idea that natural hazard-induced disasters increase income inequality not only for hurricane states (Miljkovic and Miljkovic 2014), but also for many other states across the United States. Similar results are also 
Table 2 State-specific fixed effects model results for the United States for the period 1970-2013

\begin{tabular}{|c|c|c|c|c|c|c|c|}
\hline Variable & Coefficient & Standard error & $p$ value & Variable & Coefficient & Standard error & $p$ value \\
\hline Intercept & -6.855 & 0.092 & $0.0000 * * *$ & NJ & 0.0011 & 0.0045 & 0.8091 \\
\hline $\mathrm{AZ}$ & 0.0063 & 0.0045 & 0.1592 & NM & 0.0219 & 0.0045 & $0.0000 * * *$ \\
\hline AR & 0.0127 & 0.0045 & $0.0047 * *$ & NY & 0.0199 & 0.0049 & $0.0000 * * *$ \\
\hline $\mathrm{CA}$ & 0.005 & 0.0056 & 0.3711 & $\mathrm{NC}$ & -0.0137 & 0.0045 & $0.0024 * *$ \\
\hline $\mathrm{CO}$ & 0.0096 & 0.0045 & $0.0327 *$ & ND & 0.0143 & 0.0045 & $0.0015 * *$ \\
\hline $\mathrm{CT}$ & 0.0296 & 0.0045 & $0.0000 * * *$ & $\mathrm{OH}$ & -0.0325 & 0.0045 & $0.0000 * * *$ \\
\hline $\mathrm{DE}$ & -0.0146 & 0.0045 & $0.0012 * *$ & OK & 0.0177 & 0.0045 & $0.0000 * * *$ \\
\hline DC & 0.033 & 0.0046 & $0.0000 * * *$ & OR & -0.0041 & 0.0045 & 0.3602 \\
\hline FL & 0.0354 & 0.0046 & $0.0000 * * *$ & PA & -0.0159 & 0.0046 & $0.0000 * * *$ \\
\hline GA & 0.0097 & 0.0045 & $0.0316^{*}$ & RI & -0.0105 & 0.0045 & $0.0205^{*}$ \\
\hline ID & 0.0203 & 0.0045 & $0.0000 * * *$ & $\mathrm{SC}$ & -0.0113 & 0.0045 & $0.0113 *$ \\
\hline IL & 0.0001 & 0.0046 & 0.9750 & $\mathrm{SD}$ & 0.0415 & 0.0045 & $0.0000 * * *$ \\
\hline IN & -0.0198 & 0.0045 & $0.0000 * * *$ & $\mathrm{TN}$ & 0.0057 & 0.0045 & 0.0205 \\
\hline IA & -0.0135 & 0.0045 & $0.0027 * *$ & $\mathrm{TX}$ & 0.0238 & 0.0048 & $0.0000 * * *$ \\
\hline KS & 0.0031 & 0.0045 & 0.4859 & UT & -0.0024 & 0.0045 & 0.5895 \\
\hline KY & -0.004 & 0.0045 & 0.3687 & VT & -0.0086 & 0.0045 & 0.0585 \\
\hline LA & 0.0225 & 0.0045 & $0.0000 * * *$ & VA & -0.018 & 0.0045 & $0.0000 * * *$ \\
\hline $\mathrm{ME}$ & -0.0187 & 0.0045 & $0.0000 * * *$ & WA & -0.0121 & 0.0045 & $0.0074 * *$ \\
\hline MD & -0.0184 & 0.0045 & $0.0000 * * *$ & WV & -0.0263 & 0.0045 & $0.0000 * * *$ \\
\hline MA & 0.0027 & 0.0045 & 0.5439 & WI & -0.0202 & 0.0045 & $0.0000 * * *$ \\
\hline MI & -0.0147 & 0.0045 & $0.0012 * *$ & WY & 0.0343 & 0.0045 & $0.0000 * * *$ \\
\hline $\mathrm{MN}$ & -0.0079 & 0.0045 & 0.0790 & GDP & $3.18 \mathrm{E}-08$ & $3.68 \mathrm{E}-09$ & $0.0000 * * *$ \\
\hline MS & 0.0199 & 0.0045 & $0.0000 * * *$ & Time & 0.0037 & 0.0001 & $0.0000 * * *$ \\
\hline MO & -0.0016 & 0.0045 & 0.7166 & Loss & $2.77 \mathrm{E}-13$ & $9.84 \mathrm{E}-14$ & $0.0049 * *$ \\
\hline MT & 0.0376 & 0.0045 & $0.0000 * * *$ & Nonwhite & $-2.90 \mathrm{E}-12$ & $1.85 \mathrm{E}-12$ & 0.1161 \\
\hline $\mathrm{NE}$ & 0.013 & 0.0045 & $0.0039 * *$ & Over65 & 0.0051 & 0.0082 & 0.5334 \\
\hline NV & 0.0322 & 0.0045 & $0.0000 * * *$ & Senate & -.001 & 0.001 & 0.2873 \\
\hline $\mathrm{NH}$ & -0.0153 & 0.0045 & $0.0000 * * *$ & & & & \\
\hline \multicolumn{8}{|c|}{ Significant codes: 0 “***’ 0.001 ‘**’ 0.01 ‘*’ $0.05 \because, 0.1 “ 1$} \\
\hline$R$ squared & \multicolumn{2}{|c|}{0.873} & & \multicolumn{2}{|c|}{ Akaike info criterion } & -10485.32 & \\
\hline Adj. $R$ squared & \multicolumn{2}{|c|}{0.870} & & \multicolumn{2}{|c|}{ Schwarz criterion } & -10167.47 & \\
\hline$F$ statistic & \multicolumn{2}{|c|}{266.9} & & \multicolumn{2}{|c|}{$p$ value } & $2.1 \mathrm{E}-16$ & \\
\hline
\end{tabular}

noticeable for the extended time period studied here, so the trend continues.

Table 3 shows the results for the region-specific fixed effects model with the time dependent lag variable. Results imply that between 1970 and 2013, the occurrences of natural hazard-induced disasters in all regions except the Northwest widened the income gap, so the Gini coefficients are larger. Therefore, the coefficients of all regional dummies for these regions are statistically significant except the one for the Northwest region. The Northeast region was chosen by $\mathrm{R}$ software to be the omitted region (base level), but any other region could equally serve that purpose, as the results would not be changed qualitatively.

The statistically significant coefficients are reported for GDP, economic damages, proportion of people aged 65 and over, the political makeup of the U.S. Senate (Republican versus Democrat), and time trend. The coefficient for the proportion of nonwhite people is not statistically significant.

The coefficient for GDP indicates that an increase of annual GDP by USD 1000 billion will lead to an increase in the Gini coefficient of about 0.036 or $3.6 \%$. This result is in line with the result reported for the state-level fixed effects model. The region-specific fixed effects model suggests that a $1 \%$ increase in the proportion of the population aged over 65 leads to a $4.4 \%$ increase in the Gini coefficient. This result is consistent with the suggestion made by Anbarci et al. (2005) that the losses from natural hazard-induced disasters influence the existing income inequalities more pronouncedly, especially for women, the 
Table 3 Region-specific fixed effects model results for the United States for the period 1970-2013

\begin{tabular}{|c|c|c|c|}
\hline Variable & Coefficient & Standard error & $p$ value \\
\hline Intercept & -6.766 & 0.0949 & $0.0000 * * *$ \\
\hline Northwest & 0.0039 & 0.0024 & 0.1126 \\
\hline South & 0.0168 & 0.0019 & $0.0000 * * *$ \\
\hline Southeast & 0.0001 & 0.0019 & 0.9924 \\
\hline Southwest & 0.0113 & 0.0022 & $0.0000 * * *$ \\
\hline West & 0.0189 & 0.003 & $0.0000 * * *$ \\
\hline Northern rockies and plains & 0.0303 & 0.0021 & $0.0000 * * *$ \\
\hline Upper midwest & -0.012 & 0.0022 & $0.0000 * * *$ \\
\hline Ohio valley & -0.0098 & 0.0018 & $0.0000 * * *$ \\
\hline GDP & $3.56 \mathrm{E}-08$ & $0.00 \mathrm{E}+00$ & $0.0000 * * *$ \\
\hline Senate & -0.0028 & 0.0011 & $0.0137 *$ \\
\hline Time & 0.0037 & 0.0001 & $0.0000 * * *$ \\
\hline Loss & $5.09 \mathrm{E}-13$ & $1.14 \mathrm{E}-13$ & $0.0000 * * *$ \\
\hline Over65 & 0.0438 & 0.0089 & $0.0000 * * *$ \\
\hline Nonwhite & $-2.03 \mathrm{E}-2$ & $2.17 \mathrm{E} 12$ & $0.0000 * * *$ \\
\hline \multicolumn{4}{|c|}{ Significant codes: 0 ‘***’ 0.001 '**' 0.01 '*’ 0.05 ' 0.1 ' 0.1} \\
\hline$R$ squared & 0.817 & & \\
\hline Adj. $R$ squared & 0.816 & & \\
\hline$F$ statistic & 683.5 & & \\
\hline Akaike info criterion & -9783.8 & & \\
\hline Schwarz criterion & -9693 & & \\
\hline$p$ value & $2.2 \mathrm{E}-16$ & & \\
\hline
\end{tabular}

young and elderly, and people of ethnic or racial minorities. Hence, the growth of the elder population proportion will automatically lead to a further increase in income inequality. In the region-specific model, income inequality seems not to be directly related with the proportion of nonwhite people.

The makeup of the Senate seems to be an important predictor of the Gini coefficient in the region-specific model. The base level for the Senate variable is Republican. Some people argue that although it seems that the political balance in the U.S. Senate has important implications on income distribution, in reality, there is a minimal relationship between the rise in income inequality and class-based voting (Gelman et al. 2010). The $p$ value for this variable is 0.0137 , indicating a significant relationship between political party and income inequality. Holding other variables constant, the Gini coefficient decreases by 0.003 or $0.3 \%$, if the majority of people in certain states vote for a Democratic Senate. The region-specific fixed effects model is a good fit based on the reported $R^{2}$ being equal to 0.817 . The model is also useful in the prediction as $F=683.5$ with $p$ value $=2.2 \mathrm{E}-16$.

\subsection{Discussion and Implication}

The objective of this article is to confirm that economic damages caused by all kinds of catastrophic events further increase income inequality, not only in hurricane-affected areas, but also across the United States as a whole. The results of our study have important implications for the insurance industry and policymakers who stand in a position to provide compensation to those in affected areas.

By looking at Fig. 1, relatively small changes in Gini coefficients are shown for each state in 1970, indicating small variations in income distribution across the country. The only state that stands out with a Gini coefficient above 0.5 is Idaho. However, two decades later, more states have relatively greater income inequality. States such as California, Texas, and Florida had Gini coefficients above 0.6. In 2013, states with more income inequality are mostly located along the two coasts. States such as California, Florida, Nevada, and Wyoming all had Gini coefficients that were roughly larger than 0.65 . By looking at the transitions between the three maps, an overall increase in Gini coefficients is expected. It is interesting to see the result because it affirms that as the nation develops, chances are technological innovations made by certain 
individuals or companies would further increase their own wealth, thus increase overall income inequality.

A vital takeaway from this article is that economic damages due to all kinds of natural hazards, together with GDP, time trend, and political parties serve to predict income distribution across the United States. It is normal that many people link income equality to how our economy performs, which is the GDP value for each year. But because the two major parties can respond to natural hazards differently, it is interesting to see income inequality slightly related to whether the government is primarily represented by one or the other party. In Fig. 2, there is an overall increasing trend for Gini coefficients for both parties, indicating an overall increase in income inequality. Also, there is not much difference between Gini coefficients for Republican versus Democrat before 2000. However, there has been a staggering increase in terms of Gini index whenever the majority of people in certain states have voted Republican since the early 2000s, and the gap reached its maximum in the mid-2000s. Since a higher Gini index represents larger income inequality, Fig. 2 (right) shows that on average the prevalence of income inequality is lower in Democratic states.

Natural hazard-induced disasters cause property damages, which in turn increase income inequality. The insurance industry, together with the government, could think of methods to help ease the pressures people face in impacted areas. It is likely that consequences associated with income inequality, such as high unemployment rate and crime rate, would in turn be alleviated.

By analyzing the past, we are able to have a broad understanding as to how income distribution has been affected by extreme weather conditions across the United States. The result will be critical for all parties, including policymakers, local industries, insurance companies, and residents.

\section{Conclusion}

The key finding in this study is that both property and crop damages caused by all natural catastrophes influenced income distribution in the entire United States for the period 1970-2013. Weather events across the country receive a great deal of attention in the daily news. Hurricanes leave devastating impacts on property and people in the coastal states. Midwestern states are prone to severe windstorms and tornados. Western states suffer from droughts and wildfires. With the capabilities to impose billions of dollars in economic damages and large numbers of fatalities, natural hazards are not only costly to individuals and society, but have the potential to adversely impact insurance industries, governments, and the entire national economy (Kunreuther and Michel-Kerjan 2007).

Catastrophes are unprecedented, not necessarily in terms of their strength, but in terms of the damage, fatalities, and displacement of the population they cause. Hurricane Katrina was a truly exogenous shock unlike any New Orleans had experienced in its recent history, so there were no prior conceptions and preparedness for the aftermath (Shaughnessy et al. 2010). According to Cameron and Shah (2015), people who have recently suffered catastrophic events exhibit more risk aversion in the following years than those who have not. People perceive that they will face a greater risk of a future disaster after experiencing a natural hazard-induced disaster. This change in perception of background risk is correlated to their real-life risk behaviors. The demand for life insurance in states directly affected and in neighboring states significantly increases after a catastrophe for the year of the disaster and the following years (Fier and Carson 2015). Hence, it will be very important to think about life insurance besides property insurance when viewing this potential implication of disasters on insurance demands.

Beauchamp (2012) pointed out that inequality is the single most important predictor of vulnerability to storm damage. The author reported that the variation in the wealth of individual counties alone explained $12.4 \%$ of the differences in the impact of natural hazard-induced disasters between counties. The reasons behind this are that poorer communities have fewer resources to evacuate and prepare for hurricanes, and also live in housing that is less likely to have been built to withstand nature's wrath (Miljkovic and Miljkovic 2014). Thus, the wealth distribution across the United States may have the potential to affect the aggregate insurance demand.

In the aftermath of these disasters, the government stands in a position to provide financial aid to those in the impacted areas, people are forced to relocate, businesses lose money, and insurance companies are expected to have sufficient capital to pay for the damages. Hence, we believe the results of this study are valuable to society, governments, and insurance companies in making further decisions.

Future research in this area could compare how different sources of loss data, along with other economic and sociodemographic variables, impact the overall Gini coefficient across the United States. Additionally, a spatial econometrics model can be considered that applies a spatiotemporal methodology for the purpose of studying the dynamics of the Gini coefficient in the country and for detecting significant clusters of states with similar Gini coefficients. The states that make up different clusters may vary in terms of the amount of losses suffered from natural hazard-induced disasters. These types of studies will 
further assist the insurance industry, policymakers, and state governments in enhancing current policies related to such disasters.

Acknowledgements The authors are grateful to the editors and the anonymous reviewers whose feedback and edits greatly improved the quality of this article.

Open Access This article is distributed under the terms of the Creative Commons Attribution 4.0 International License (http://crea tivecommons.org/licenses/by/4.0/), which permits unrestricted use, distribution, and reproduction in any medium, provided you give appropriate credit to the original author(s) and the source, provide a link to the Creative Commons license, and indicate if changes were made.

\section{References}

Adger, W.N. 2000. Social and ecological resilience: Are they related? Progress in Human Geography 24(3): 347-364.

Anbarci, N., M. Escaleras, and C.A. Register. 2005. Earthquake fatalities: The interaction of nature and political economy. Journal of Public Economics 89(9): 1907-1933.

Beauchamp, Z. 2012. How economic inequality makes hurricanes more deadly. ThinkProgress. https://thinkprogress.org. Accessed 18 Apr 2017.

Brunkard, J., G. Namulanda, and R. Ratard. 2008. Hurricane Katrina deaths, Louisiana, 2005. Disaster Medicine and Public Health Preparedness 2(4): 215-223.

Cameron, L., and M. Shah. 2015. Risk-taking behavior in the wake of natural disasters. The Journal of Human Resources 50(2): 484-515.

Cavallo, E., and I. Noy. 2010. The economics of natural disasters. IDB working paper series, IDB-WP-124. Washington, DC: Inter-American Development Bank.

Cavallo, E., S. Galiani, I. Noy, and J. Pantano. 2013. Catastrophic natural disasters and economic growth. Review of Economics and Statistics 95(5): 1549-1561.

Changnon, S.A. 1996. The great flood of 1993: Causes, impacts, and responsibilities. Boulder, CO: Westview Press.

Cutter, S.L., L. Barnes, M. Berry, C. Burton, E. Evans, E. Tate, and J. Webb. 2008. A place-based model for understanding community resilience to natural disasters. Global Environmental Change 18(4): 598-606.

Fier, S., and J. Carson. 2015. Catastrophes and the demand for life insurance. Journal of Insurance Issues 38(2): 125-156.

Fomby, T., Y. Ikeda, and N. Loayza. 2013. The growth aftermath of natural disasters. Journal of Applied Econometrics 28(3): 412-434.

Gelman, A., L. Kenworthy, and Y.S. Su. 2010. Income inequality and partisan voting in the United States. Social Science Quarterly 91(5): 1203-1219.

Hazards \& Vulnerability Research Institute. 2015. The spatial hazard events and losses database for the United States (SHELDUS), Version 14.0. R Foundation for Statistical Computing, University of South Carolina. http://www.sheldus.org/. Accessed 11 Oct 2017.

Ibarraran, M.E., M. Ruth, S. Ahmad, and M. London. 2009. Climate change and natural disasters: Macroeconomic performance and distributional impacts. Environment, Development and Sustainability 11(3): 549-569.

ICAT Damage Estimator. 2017. Web site. http://www.icatdamagees timator.com/. Accessed 18 Apr 2017.
Kim, C.K. 2011. The effects of natural disasters on long-run economic growth. Michigan Journal of Business 4(1): 11-49.

Klomp, J. 2016. Economic development and natural disasters: A satellite data analysis. Global Environmental Change 36: 67-88.

Kunreuther, H.C., and E.O. Michel-Kerjan. 2007. Climate change, insurability of large-scale disasters and the emerging liability challenge (No. w12821). Cambridge, MA: National Bureau of Economic Research.

Leichenko, R., and J.A. Silva. 2014. Climate change and poverty: Vulnerability, impacts, and alleviation strategies. Wiley Interdisciplinary Reviews: Climate Change 5(4): 539-556.

Logan, J.R. 2008. Unnatural disaster: Social impacts and policy choices after Katrina. In Natural disaster analysis after Hurricane Katrina: Risk assessment, economic impacts and social implications, ed. H.W. Richardson, P. Gordon, and J.E. Moore II, 279-297. London: Edward Elgar Publishing.

Majumdar, S., and M.D. Partridge. 2009. Impact of economic growth on income inequality: A regional perspective. Paper presented at the Agricultural and Applied Economics Association 2009 AAEA and ACCI Joint Annual Meeting, Milwaukee, Wisconsin, 26-29 July 2009.

Masozera, M., M. Bailey, and C. Kerchner. 2007. Distribution of impacts of natural disasters across income groups: A case study of New Orleans. Ecological Economics 63(2-3), 299-306.

Miljkovic, T., and D. Miljkovic. 2014. Modeling impact of hurricane damages on income distribution in the coastal US. International Journal of Disaster Risk Science 5(4): 265-273.

Morgan, J. 1962. The anatomy of income distribution. Review of Economics and Statistics 44: 270-283.

Nakata, H., and Y. Sawada. 2007. Demand for non-life insurance: A cross-country analysis. CIRJE Working Paper F-46. Tokyo: Center for International Research on the Japanese Economy, University of Tokyo.

Norris, F.H., S.P. Stevens, B. Pfefferbaum, K.F. Wyche, and R.L. Pfefferbaum. 2008. Community resilience as a metaphor, theory, set of capacities, and strategy for disaster readiness. American Journal of Community Psychology 41(1-2): 127-150.

Pielke Jr, R.A., J. Gratz, C.W. Landsea, D. Collins, M.A. Saunders, and R. Musulin. 2008. Normalized hurricane damage in the United States: 1900-2005. Natural Hazards Review 9(1): 29-42.

R Core Team. 2016. R: A language and environment for statistical computing. R Foundation for Statistical Computing, Vienna, Austria. https://www.R-project.org/. Accessed 20 Apr 2017.

Shaughnessy, T.M., M.L. White, and M.D. Brendler. 2010. The income distribution effect of natural disasters: An analysis of Hurricane Katrina. Journal of Regional Analysis \& Policy 40(1): 84-95.

Sproles, C.A. 2015. State of the climate: Global analysis - Annual 2014. Choice: Current Reviews for Academic Libraries 52(11): 1872.

United States Bureau of Economic Analysis. 2017. Regional data: GDP \& personal income. http://www.bea.gov. Accessed 18 Apr 2017.

United States Census Bureau. 2017. Population estimates at state level. http://www.census.gov/popest/data/historical/index.html. Accessed 18 Apr 2017.

U.S. Income Inequality Page of Mark W. Frank. 2015. http://www. shsu.edu/eco_mwf/inequality.html. Accessed 18 Apr 2017.

Yun, S.D., and B.S. Waldorf. 2016. The day after the disaster: Forced migration and income loss after hurricane Katrina and Rita. Journal of Regional Science 56(3): 420-441.

Wisner, B., P. Blaikie, T. Cannon, and I. Davis. 2004. At risk: Natural hazards, people's vulnerability and disasters, 2nd edn. London: Routledge. 